\title{
Sobre a "Crise" do Estado de Bem-Estar: Retração, Transformação Fáustica ou o Quê?
}

\section{Celia Lessa Kerstenetzky}

Professora titular do Departamento de Ciência Política da Universidade Federal Fluminense (UFF), pesquisadora do Conselho Nacional de Desenvolvimento Científico e Tecnológico (CNPq) e diretora do Centro de Estudos sobre Desigualdade e Desenvolvimento (CEDE). E-mail: celiakersten@gmail.com

\section{INTRODUÇÃO}

C onquanto o problema de se haveria ou não uma crise do estado de bem-estar tenha estimulado um conjunto expressivo de contribuições, o retorno a ele se justifica por pelo menos duas razões. Em primeiro lugar, a necessidade de sistematizar essas contribuições; em segundo lugar, a importância de se avançar a partir da constatação de uma crise ou não crise em direção a outros dilemas que se apresentem. Neste artigo, tentaremos, pois, sistematizar a questão de se o estado de bem-estar estaria em crise visando, em última instância, o horizonte mais amplo de transformação do mesmo. Esse exame é dependente, como é natural, de definições operacionais de welfare state e crise. Para fins deste artigo, definiremos o welfare state como um conjunto de intervenções públicas visando à promoção de bem-estar e envolvendo (algum grau de) redistribuição de renda. A definição de crise é mais problemática, tendo variado substancialmente no debate público das últimas décadas. Enquanto algumas definições rapidamente perderam credibilidade, como as que anunciavam já nos anos 1970 o fim iminente do estado de bem-estar por conta de constitutivas contradições internas, agudizadas por seu crescimento incontido, outras, evocando noções mais vagas de problemas crônicos e em larga escala, parecem resistir melhor. Na realidade, a doutrina um tanto paradoxal de um estado de crise permanente remonta aos anos dourados de expansão do

DADOS - Revista de Ciências Sociais, Rio de Janeiro, vol. 55, n²2, 2012, pp. 447 a 485. 
welfare state, quando argumentos conservadores advertiam sobre os efeitos econômicos deletérios da intervenção social estatal. Porém, nunca antes como crescentemente nas três últimas décadas esses argumentos ganharam tanta ressonância. O objetivo preliminar deste artigo é examinar o grão de verdade na proposição de uma crise do estado de bem-estar.

Após uma breve discussão sobre possíveis significados de crise, na primeira seção, tal exame é empreendido tomando por base um conjunto de indicadores quantitativos e qualitativo-quantitativos normalmente associados à presença de um welfare state, na seção seguinte. Essa primeira aproximação fornece uma base razoavelmente sólida para refutarmos a tese de crise, iminente ou crônica. Todavia, inegavelmente algo aconteceu nas décadas recentes. A terceira seção estuda então um fenômeno relativamente diferente de "crise": mudança. Nela, observaremos e avaliaremos as pressões sentidas e as transformações ocorridas, que implicaram, um tanto contraditoriamente, privatização da provisão de bem-estar e expansão da intervenção pública. Resta saber se as mudanças negociaram a alma do estado de bem-estar - a "transformação fáustica" a que se refere o título - no sentido de nossa definição anterior: intervenção pública promotora de bem-estar via redistribuição. Este é o tema da quarta seção. A última seção conclui o artigo com a observação de que se o fantasma da crise está de certo modo afastado - no sentido de terem as instituições do welfare state sido absorvidas como um aspecto permanente do ambiente socioeconômico das sociedades contemporâneas - é ainda necessário conhecer o impacto das transformações sobre a capacidade do estado de bem-estar seguir promovendo redistribuição e suas instituições seguirem pertencendo ao “domínio público".

\section{CRISE?}

Segundo Pierson (1998), é possível atribuir quatro significados à noção de crise: situação de perturbação causada por um choque externo (1), manifestação de uma contradição de longo prazo (2), momento dramático que precede a superação de uma situação (3) ou qualquer problema em larga escala e duradouro (4).

A tese de um choque externo (1) causado pela crise do petróleo teve alguma aceitação durante os anos 1970, porém, as teses mais difundidas nos anos 1970 e 1980 privilegiaram o significado de crise como mani- 
festação de uma contradição de longo prazo (2), tendo sido defendidas seja por autores "neomarxistas" seja pela chamada nova direita. O diagnóstico, à esquerda, de uma crise do Estado resultante de contradição interna a sua concepção (representar uma classe e seus interesses e buscar legitimidade na classe antípoda e atender seus interesses) [O'Connor, 1973], e o diagnóstico, à direita, de um excesso de demandas sobre o Estado causadas pelas expectativas criadas pela democracia (Crozier et alii, 1975), apontavam ambos para a iminência de transformações estruturais disparadas pelo desequilíbrio nas finanças públicas e que culminariam no fim do estado de bem-estar (Pierson, 1998).

As previsões de um fim iminente do welfare state não se materializariam. Evidências de uma crise contingente, causada por um choque externo, foram mais convincentes. Os dois choques do petróleo da década de 1970 e mais uma série de transformações econômicas que os acompanharam ${ }^{1}$ contribuíram para reduzir o nível de atividade econômica e, finalmente, mergulhar vários países em uma recessão importante e níveis de desemprego inéditos no pós-guerra. As várias "titularidades" $^{2}$ à proteção social estavam asseguradas; honrá-las, diante de uma receita pública que se contraía junto com o nível de atividade, significou déficits e dívidas públicas que agravaram o quadro econômico.

Pode este quadro ser caracterizado como uma crise do welfare state? A causa material foi econômica, não social ou política, diferentemente do previsto nas duas versões de "contradição de longo prazo". Pode-se, todavia, objetar que, mesmo não tendo sido o agente causador da crise econômica (cuja fonte externa é claramente identificável), o estado de bem-estar teria contribuído para acentuá-la e, ao fazê-lo, provocar sua própria crise financeira - uma situação insustentável que tem de ser descontinuada (3).

A evidência, contudo, é que a crise de financiamento - como situação que tem que ser descontinuada - não ocorreu: o gasto social seguiu trajetória ascendente a despeito da crise econômica (voltaremos à análise da evidência na próxima seção). Com um produto estagnado ou mesmo decrescente, o crescimento do gasto social foi sustentado em parte à custa de uma redução em outras áreas do gasto público, que ao fim e ao cabo acusou retração relativa nos anos 1980 e 1990 (Castles, 2004).

Resta o significado de crise como "um problema de larga escala e duradouro" (4). O "problema" se resumiria ao custo crescente de um estado 
de bem-estar. A percepção do welfare state como, nesse sentido, um problema emerge com o fim da "sociedade do crescimento", o contrato social lastreado no crescimento econômico que caracterizou o pós-guerra e sustentou o consenso político dos "anos dourados" do estado de bem-estar (1945-1975). Trata-se agora da existência de titularidades sociais mais ou menos rígidas frente a uma demanda em expansão e a uma economia que perde dinamismo. A "desnaturalização" da sociedade do crescimento teria sido acompanhada pela desnaturalização do welfare state.

Podemos nos perguntar até que ponto a representação do estado de bem-estar como problema é coerente. Se nos ativermos às titularidades da seguridade social ${ }^{3}$, há argumentos econômicos convencionais para elas. Segundo Barr (2001), mesmo que as sociedades contemporâneas fossem "sociedades de classe média", isto é, "igualitárias", o estado de bem-estar seguiria sendo necessário. E a razão principal é a existência de riscos e incerteza nas economias de mercado contemporâneas, diz ele, ecoando argumentos de Titmuss (1974). Os programas da seguridade social cobrem riscos e incerteza não asseguráveis privadamente, como desemprego e inflação. Eles também contribuem para a suavização do consumo, isto é, o equilíbrio entre despesa e poupança necessário para se atingir o padrão de consumo mais alto possível ao longo da vida. O financiamento público à saúde é um efetivo seguro contra riscos médicos não cobertos por seguro privado, enquanto o financiamento público à educação garante o arriscado e incerto investimento em educação no início da vida. Finalmente, os programas da seguridade protegem contra a pobreza extrema. Em suma, a compreensão do welfare state como mero custo se abstrairia da noção de que ele também representa um benefício e que a "racionalidade social" requereria, mesmo na argumentação econômica convencional, não que fosse minimizado, mas "otimizado", que seu tamanho e sua composição fossem avaliados levando-se em consideração custos e benefícios, de modo a refletir a escolha social entre objetivos como "segurança" e "crescimento" (Barr, 2001). Em face dos novos riscos sociais, as razões contemporâneas para a existência do estado de bem-estar como um piggy bank permanecem tão ou mais importantes e urgentes que as que motivaram sua construção no pós-guerra. Novos riscos exigem novas formas de proteção, necessárias, por sua vez, para viabilizar a vida normal de uma economia de mercado.

Mas também sob o ponto de vista do crescimento econômico, pode o welfare state aportar contribuição, lembra Barr (2001). Esta se materiali- 
za, por exemplo, em um sistema de seguro-desemprego que viabilize (e compense) a mobilidade do trabalho e encoraje a assunção de riscos ou, ainda, em um bem desenhado sistema de empréstimos para estudantes de terceiro grau que facilite o investimento em educação superior (Barr, 2001). Ou seja, há certa interação entre "segurança" e "crescimento". Esping-Andersen $(1999,2009)$ argumenta ainda que o impacto do welfare state na equalização das chances de vida ${ }^{4}$, por meio da mais ampla oferta de oportunidades iguais e de proteção social, é um ingrediente crucial para o crescimento sustentado. Esse conjunto de funções parece ainda mais premente nos novos tempos de empregos instáveis, desemprego duradouro e aumento das desigualdades econômicas e sociais.

Contudo, os anos 1990 testemunharam uma retomada da tese da crise, no sentido de (3) (momento dramático que precede a superação de uma situação difícil), apoiada, dessa vez, nos fatos recentes da globalização e das mudanças demográficas (Castles, 2004).

No primeiro caso, o fator restritivo não seria a crise econômica e sim as transformações estruturais na economia mundial. Estas se apresentam sob a forma de eliminação de barreiras à competição econômica ao nível global, em particular, à mobilidade de capitais, que leva à redução de impostos e queda generalizada dos gastos sociais dos países ("corrida para o fundo"). Se, por um lado, os recursos estariam, desse modo, limitados, por outro, mudanças estruturais na composição da população, como o aumento da expectativa de vida e a queda nas taxas de fecundidade, inviabilizariam o congelamento do montante de titularidades ao mesmo tempo em que restringiriam ainda mais os recursos disponíveis para honrá-las. Isso porque, enquanto a longevidade aumenta a razão de dependência, esta é magnificada pela redução das taxas de fecundidade: um número crescente de dependentes inativos passa a ser sustentado por um número decrescente de pessoas ativas. Essas duas novas fontes de dificuldades ressuscitariam a tese da crise como "situação que não pode se perpetuar e requer uma descontinuidade" (3).

Não obstante o seu apelo lógico, a "tese da globalização" é controversa, não tendo sido corroborada pela evidência (cf. Koster, 2009, que faz uma revisão exaustiva da evidência disponível). Castles (2004), por exemplo, demonstra que a globalização não tem impacto significativo sobre o desenvolvimento do welfare state (as variáveis mais importan- 
tes em seu modelo foram o crescimento econômico, o grau de maturação dos programas e governos de esquerda) ${ }^{5}$. Quanto à tese da pressão demográfica, de fato o envelhecimento é um fator relevante, sobretudo quando se considera que mais de dois terços do gasto social se destinam à população idosa, seja em forma de renda seja de serviços de saúde e cuidado. Contudo, pode se alegar que essa pressão não é exatamente um problema do estado de bem-estar e sim um problema para o estado de bem-estar, no sentido de ser um problema social típico de ser enfrentado via um arranjo institucional como o welfare state. Assim como o incremento proporcional da população idosa, também as taxas de fecundidade declinantes são um problema da sociedade como um todo (famílias, setor privado de provisão de bem-estar e setor público). O estado de bem-estar pode ser parte da solução quando, por exemplo, viabiliza a conciliação da vida familiar com o trabalho, permitindo a retomada de taxas positivas de crescimento populacional, algo que já se observa nos países nórdicos, mas também quando equaliza chances de vida aumentando o potencial produtivo da população e sua capacidade de sustentar uma população idosa (Esping-Andersen, 1999, 2009).

Em ainda outro sentido, o estado de bem-estar pode ser visto como um problema: é uma instituição que cria sua própria defesa política, tendendo, portanto, a um desenvolvimento inercial. Praticamente todos os integrantes das sociedades contemporâneas são de algum modo seus beneficiários, e um bom número deles está empregado em ocupações relacionadas à provisão de serviços e aos programas de sustentação de renda que constituem seu âmago. Essa massa de beneficiários diretos representa uma força política importante. Importante a ponto de autores como Paul Pierson (1996) sustentarem que a política do welfare state mudou: não é mais a política dos sindicatos e partidos da social-democracia do pós-guerra, mas a política de sua clientela e de seus empregados. De um modo geral, reformas retracionistas tendem a encontrar obstáculos apreciáveis contrapostos por essas constituencies. Naturalmente, alguns programas sociais são mais suscetíveis de despertar reação organizada a sua retração do que outros, por exemplo, as aposentadorias, em relação ao seguro-desemprego ou a programas de alívio à pobreza. Assim mesmo, mudanças principalmente incrementais têm sido observadas nas últimas décadas, como adaptações às novas circunstâncias, e podem ser melhor apreciadas contra o pano de fundo dos diferentes regimes de bem-estar e suas economias políticas, o que escapa ao escopo deste artigo ${ }^{6}$. 
Resta a questão de saber o que aconteceu a partir dos anos 1970 que nos permita compreender a ansiedade quanto ao fim do welfare state. É o que começaremos a fazer na próxima seção.

\section{A CRISE QUE NÃO ACONTECEU}

Nesta seção, recuperaremos a evidência empírica quanto à (in)existência de vestígios de crise iminente do welfare state nos sentidos (1), (2) e (3) e registraremos alguns sinais de descontinuidade em relação à trajetória dos anos dourados.

O estudo de Arts e Gelissen (2010), com base nos dados da Organização para a Cooperação e Desenvolvimento Econômico (OECD) para os anos de 1990 e 2005/6, não encontrou evidência de retração do welfare state. De fato, a observação simples da série de gasto público social de 22 países da OECD entre os anos de 1980 e 2007 (OECD, 2009) revela que o gasto cresceu ao longo do período, a um ritmo superior ao do crescimento médio do produto (Gráfico 1). Este, por sua vez, apresentou taxa de crescimento positiva ao longo do período, de modo que a magnitude absoluta de recursos destinados pelos países da OECD ao gasto social foi crescente (Gráfico 2). Ademais, a taxa de crescimento flutuou bem mais que a proporção do gasto social no produto. Comple-

Gráfico 1

Gastos Sociais como \% PIB - OECD

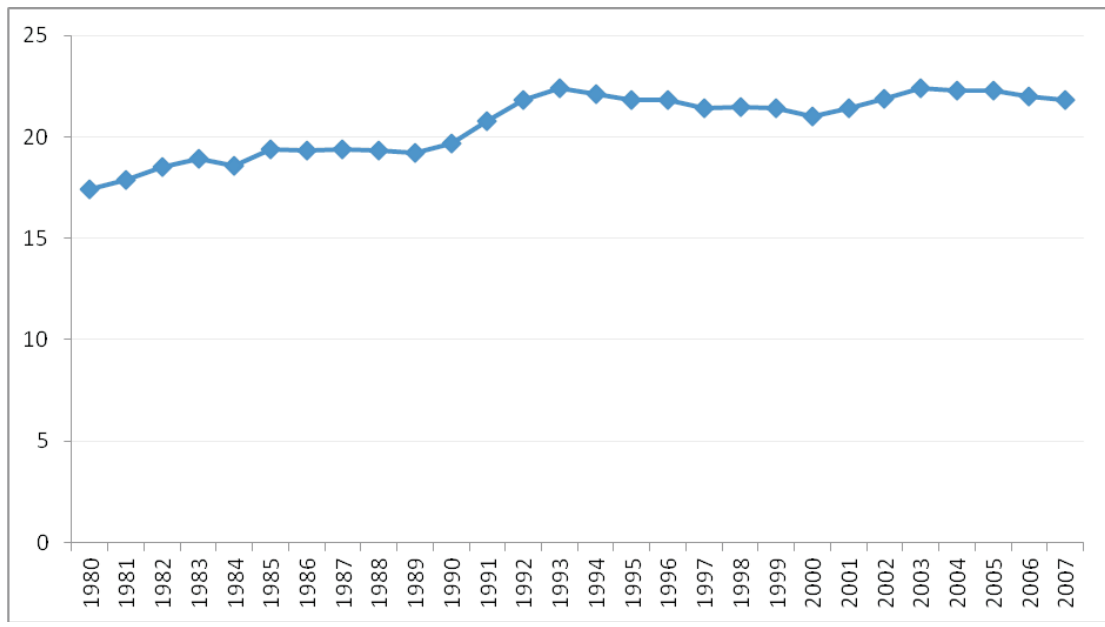

Fonte: Elaboração própria, dados de OECD (2009). 
Gráfico 2

Taxa de Crescimento do PIB - OECD

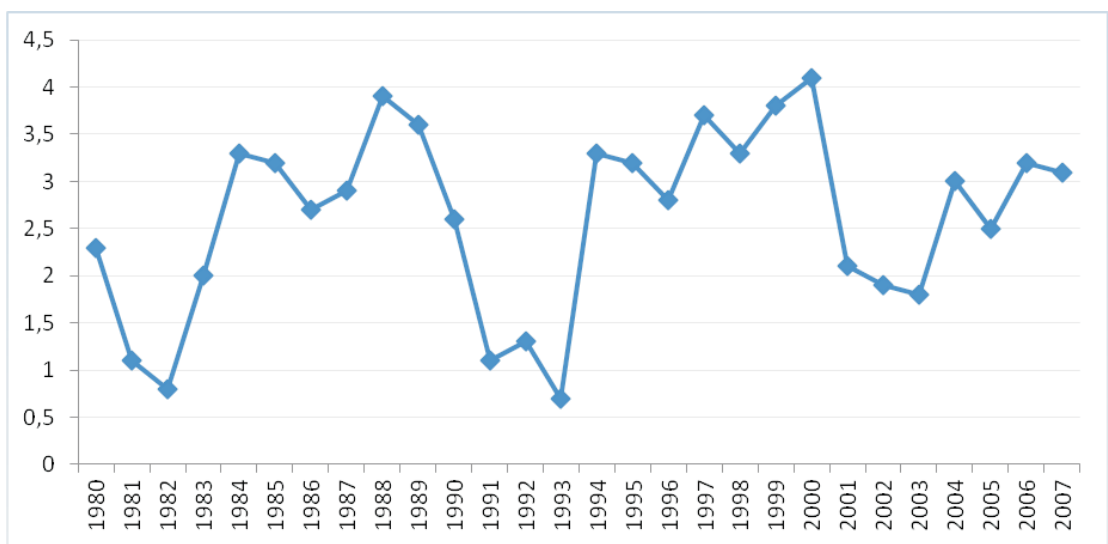

Fonte: Elaboração própria, dados de OECD (2009).

mentarmente, OECD (1988) plotou o crescimento contínuo do gasto social, acima do produto, entre os anos de 1965 e 1985. Em conjunto, pois, a evidência quanto ao gasto revela mais de quatro décadas de expansão, em termos relativos e absolutos.

O estudo mais sistemático sobre mudanças no montante e composição do gasto social pós-anos dourados é o de Castles (2004), parcialmente atualizado por Starke et alii (2008) com um controle para as diferentes estruturas demográficas e de mercado de trabalho na área da OECD. Vamos sintetizar os principais resultados de Castles (2004).

Castles (2004) testou a hipótese de crise por meio de um conjunto de indicadores quantitativos e qualitativos. Com base nas estatísticas da OECD (SOCX), o autor coletou informações para 22 países da OECD, entre os anos de 1960, 1980 e 1998. A compilação dos dados referentes aos gastos sociais revelou expansão contínua e redução da dispersão entre os países, em todos os indicadores quantitativos considerados, revelando uma "convergência para cima" no lugar de uma "corrida para o fundo". Esse resultado é confirmado por Starke et alii (2008), por meio da utilização de dois indicadores de convergência (redução das medidas de dispersão e relação negativa entre valor inicial e taxa de crescimento do gasto, ou catch up) e incluindo o ano de 2003.

O indicador convencional de gasto social público como percentual do PIB se expandiu no período, revelando que, em consonância com o comportamento observado no pós-guerra, o gasto aumentou mais do 
que o produto. Mas como o produto per capita praticamente estagnou ou mesmo declinou em alguns anos no período entre 1980-1998, tal situação poderia camuflar uma redução de facto do montante médio de recursos alocados ao gasto social. Para checar tal hipótese, o autor coletou dados sobre o gasto social per capita em termos reais. O resultado é que também esse indicador revelou um crescente comprometimento de recursos. Poderia ser ainda alegado que, com a contração do nível de atividade e o consequente aumento do desemprego, as necessidades sociais estariam se expandindo e mesmo uma maior quantidade de recursos em termos reais poderia esconder um déficit de efetividade de um gasto que não estaria acompanhando necessidades crescentes. Para verificar tal possibilidade, Castles (2004) construiu o indicador razão do gasto social sobre necessidades, medido como razão entre o gasto social como percentual do PIB e o percentual da população dependente (percentual de pessoas com 65 anos ou mais somado ao percentual de desempregados). Também nesse caso, a hipótese da contração foi falsificada, pois essa razão aumentou continuamente ao longo do período. Finalmente, um indicador do gasto social real por dependente também revelou expansão ao longo do período em que se esperava retração (ver Anexo 1, Tabela 2).

Os gráficos 3 e 4 sumarizam os resultados referentes aos gastos, enquanto o Gráfico 5 revela a redução na dispersão entre os países:

Gráfico 3

Indicadores de Gasto Social (\%)

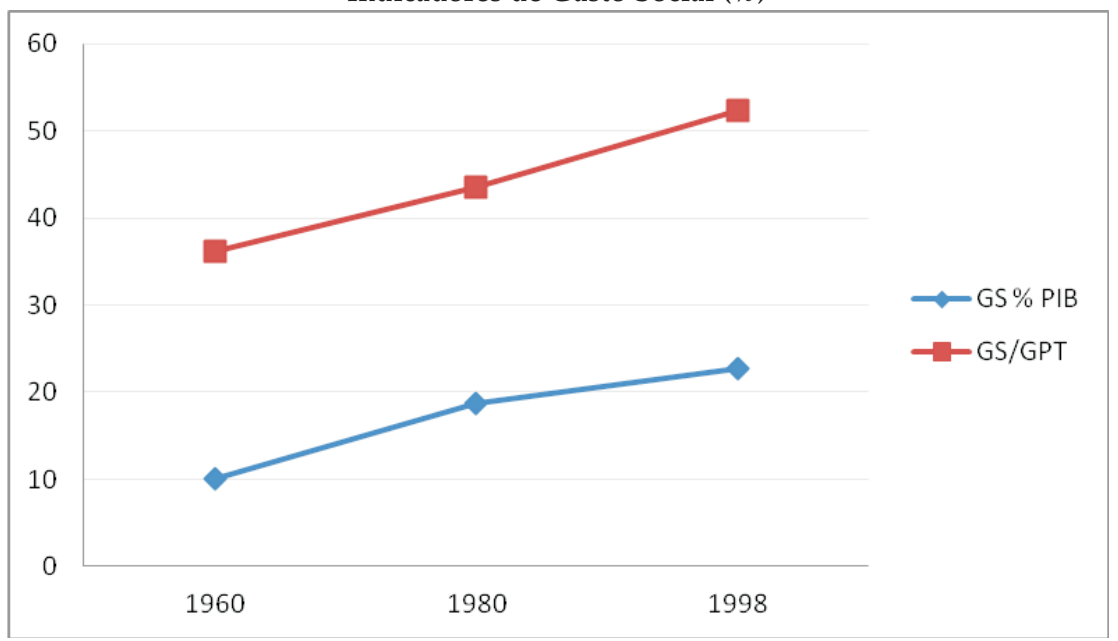

Fonte: Elaboração própria com base em dados de Castles (2004). GS = gasto público social; GS/GPT = gasto público social sobre gasto público total; GS / dependente = gasto público social por dependente. 
Gráfico 4

Indicadores de Gasto Social

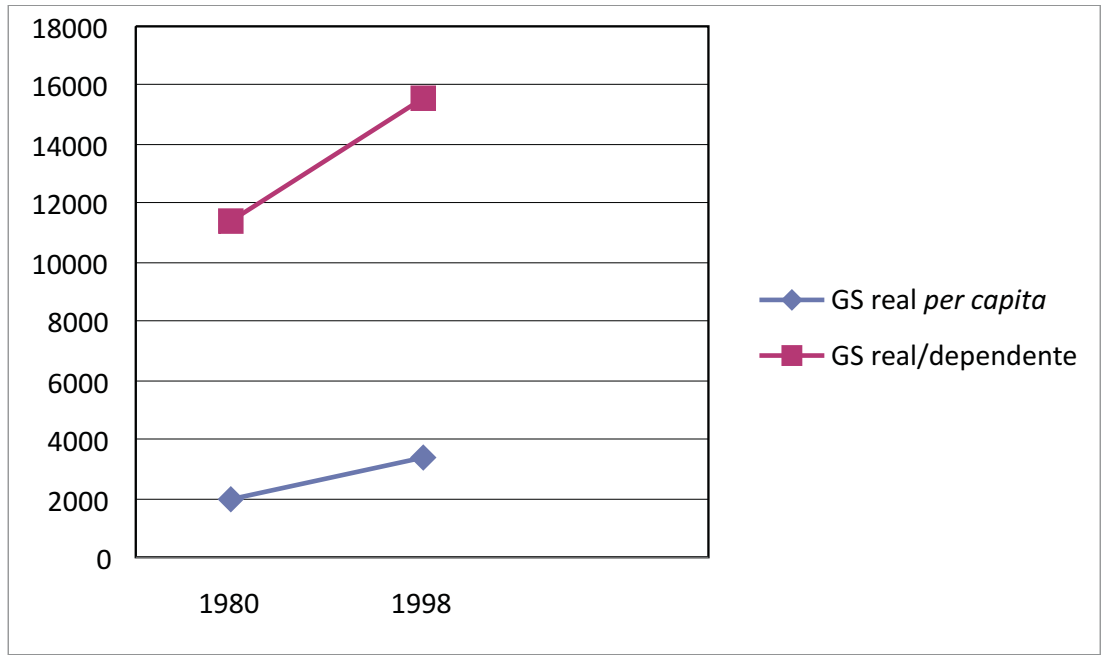

Fonte: Elaboração própria com base em dados de Castles (2004). GS = gasto público social; GS/GPT = gasto público social sobre gasto público total; GS/dependente = gasto público social por dependente.

\section{Gráfico 5}

Coeficientes de Variação

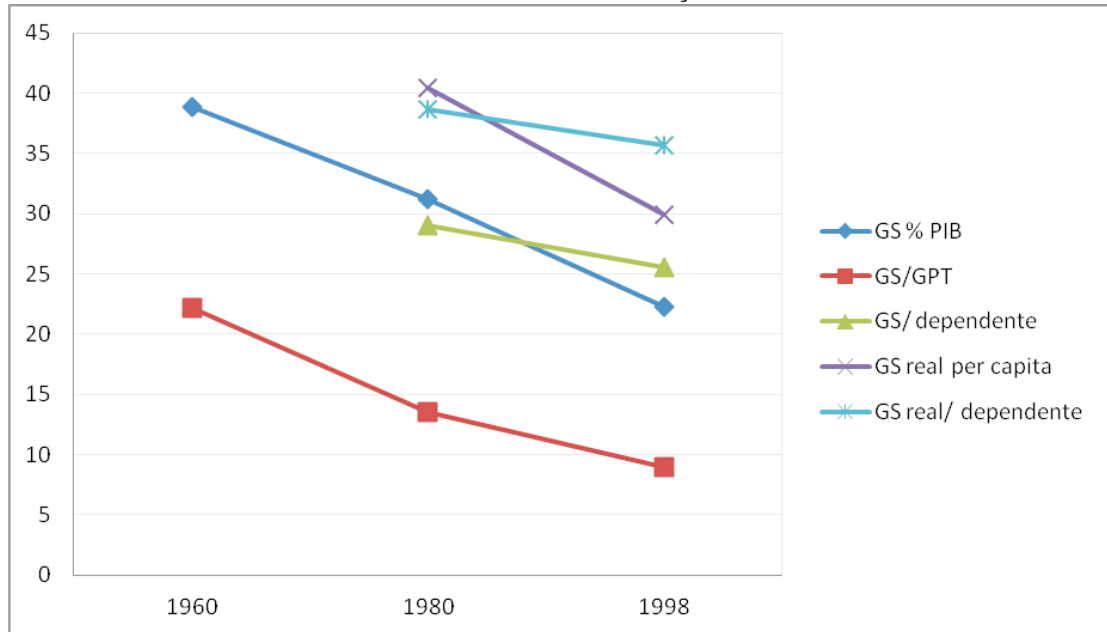

Fonte: Elaboração própria com base em dados de Castles (2004).

Os dados de Castles refutam a hipótese de crise iminente e mostram um welfare state que deita raízes profundas em todos os países do bloco. Essa observação é reforçada pelos dados referentes à participação do gasto social dentro do gasto público dos países, que é crescente ao lon- 
go do período, revelando a sua progressiva prioridade nas décadas recentes. Os países da OECD chegam ao final dos anos 1990 com um gasto social médio superior a $50 \%$ do gasto público (com pouco menos de $50 \%$ estão apenas os EUA e o Reino Unido). Nossas próprias estimativas para o ano de 2007 mostram que os indicadores quantitativos do gasto social não sofreram quebra de crescimento na década de 2000. Apesar da pequena redução observada na relação gasto/produto em 2007 em relação a 1998, o montante real de recursos comprometidos, seja per capita seja por dependente, aumentou significativamente. Quanto à convergência, observada entre os anos 1980 e 1998, que se confirmou para o gasto social sobre o produto e o gasto social sobre o gasto público, não ocorreu quanto ao gasto real per capita ou por dependente entre os anos 2000 e 2007, o que nos remete à diferenciação entre os "regimes" (ver Anexo 2, gráficos 6, 7 e 8).

Todavia, os dados referentes aos gastos poderiam ser opacos em relação a transformações qualitativas: mesmo com um gasto crescente, a composição deste poderia estar se alterando em termos de prioridades ou de recursos destinados a programas tradicionais - por exemplo, o seguro-desemprego substituindo a saúde. Castles construiu alguns indicadores para observar essas mudanças, a partir de dados desagregados para os principais programas sociais, disponíveis na base do SOCX OECD: um indicador de mudança estrutural; outro, para captar cortes em programas; e um terceiro, para observar uma possível tendência à residualização dos welfare states.

O indicador de mudança estrutural procurou rastrear modificações na composição do gasto entre 1980 e 1998 (em termos de 11 ou 12 componentes, este último conjunto inclui seguro-desemprego). O indicador de cortes em programas buscou observar essas mesmas alterações computando eventuais cortes em 1998 como percentual do gasto na rubrica em $1980^{7}$. Ambas as medidas mostram pequenas alterações na estrutura do gasto (cerca de $8 \%$ nos dois indicadores, no período de duas décadas), uma grande variação nacional e a ausência de um padrão claro por família de países ou regime. Por exemplo, a Suécia e o Reino Unido se destacaram com as maiores mudanças. No caso da Suécia, a recessão dos anos 1990, com desemprego em massa, foi um fator importante na definição de novas prioridades; no caso da Inglaterra, a tentativa do governo Thatcher de desmantelar o welfare state, mesmo não aparecendo no montante do gasto, se fez sentir na alteração de sua estrutura. 
O terceiro indicador qualitativo de retração do welfare state visou captar uma possível residualização do gasto social, com a ênfase "liberal" nos programas de alívio à pobreza ganhando realce sobre programas como a seguridade social e os serviços sociais providos pelo Estado. Ao contrário do esperado, contudo, houve um declínio na participação relativa dos programas de alívio à pobreza no período 1980-1998, observado em 15 dos 22 países da OECD (apenas no grupo de países de língua inglesa é que se notou o aumento esperado). Na média, observou-se um aumento na participação relativa dos serviços providos pelo Estado, o que ocorreu em 18 dos 22 países.

A análise de Castles desce ainda ao nível de países e "famílias" de países que compartilhariam características comuns: Europa Ocidental Continental, Europa Mediterrânea, Escandinávia e países de língua inglesa ${ }^{8}$. A esses, ele acrescenta, como casos idiossincráticos, o Japão e a Suíça. Vários aspectos da análise relativos a gastos mostram uma convergência entre os países, não em direção ao fundo, mas ao topo, como já mencionado. Já a análise de elementos estruturais confirma a existência de regimes de bem-estar, especialmente a distribuição diferenciada do gasto entre programas de alívio à pobreza (cuja ênfase é típica dos países anglo), seguridade social (típica da Europa Continental) e serviços sociais públicos (típicos dos países nórdicos). Portanto, outra via de retração, que seria observada pela convergência dos países em direção à estrutura de gastos da família anglo-saxã, não encontrou comprovação. Assim, por exemplo, uma pequena, porém, generalizada redução em seguridade social é mais modesta ainda no grupo de países da Europa Ocidental, enquanto os países de língua inglesa têm o maior aumento relativo em programas de alívio à pobreza, e os escandinavos, o maior aumento médio em serviços (Tabela 1). Na mesma linha, Starke et alii (2008), com base em um conjunto mais extenso de indicadores e dados até o ano de 2003, não encontram evidência de residualização ou "americanização" dos welfare states da área da OECD.

A conclusão otimista de Castles (2004:21) é a seguinte: "A feição geral dos estados do bem-estar ocidentais mudou pouco, com a redução em algumas áreas sendo compensada pela expansão em outras, e as diferenças entre eles, em termos de prioridades, se mantido, a única alteração notável tendo sido um ligeiro deslocamento geral em direção à provisão pública de serviços" (tradução livre). Confirmando essa conclusão, Starke et alii (2008) observam expansão absoluta em transferências monetárias e em serviços, entre 1980 e 2003, com o crescimento re- 
Sobre a "Crise" do Estado de Bem-Estar: Retração, Transformação Fáustica...

Tabela 1

Composição \% do Gasto Social por "Família" (Regime)<R>1980 e 1998

\begin{tabular}{l|c|c|c|c|c}
\hline & & Anglo & Nórdica & Continental & Mediterrânea \\
\hline Seguridade social & 1980 & 45,9 & 45,7 & 56,3 & 62,2 \\
\hline \multirow{3}{*}{ Alívio à pobreza e saúde } & 1998 & 43,7 & 43,2 & 54,8 & 65 \\
\hline & 1980 & 51,4 & 41,1 & 39,8 & 36,8 \\
\hline Serviços sociais & 1998 & 52,9 & 38,7 & 38,9 & 31,9 \\
& 1980 & 2,7 & 13,2 & 4 & 2 \\
& 1998 & 3,3 & 18,1 & 6,3 & 3,1 \\
\hline
\end{tabular}

Fonte: Elaboração própria, com base em dados de Castles (2004). Anglo: Austrália, Canadá, Estados Unidos, Irlanda, Nova Zelândia e Reino Unido; Nórdica: Dinamarca, Finlândia, Noruega e Suécia; Continental: Alemanha, Áustria, Bélgica, França e Holanda; Mediterrânea: Espanha, Grécia, Itália, Portugal.

lativo dos serviços. A tendência observada de convergência do gasto total como proporção do produto também foi confirmada.

A análise capta ainda uma inflexão no ritmo de crescimento no período 1980-1998, aspecto observado também por outros autores (Pierson, 1998), que corresponderia ao alcance de certa maturidade e estabilidade. As taxas médias escondem, porém, o catching up e, finalmente, liderança dos países escandinavos, que se estabelece justamente a partir dos anos 1980 e se encontra consolidada ao final dos anos 1990 (Castles, 2004). A análise mostra também uma estagnação do gasto público na OECD (crescimento médio positivo de 0,7\%) entre 1980 e 1998 - na verdade, uma redução de sua participação em um produto que em alguns anos decresceu, revelando a crescente prioridade concedida ao bem-estar social.

\section{MAS ALGO ACONTECEU, O QUÊ?}

Autores como Huber e Stephens (2001) observam alterações significativas nas atitudes dos políticos e um novo espírito encarnado nas reformas propostas nos anos 1980. Em sua interpretação, enquanto os eventos econômicos desfavoráveis dos anos 1970 teriam sido inicialmente percebidos como mero soluço em uma trajetória gloriosa, a partir dos anos 1980 as coisas mudariam. Essas mudanças se manifestaram, inicialmente, em discursos públicos enfatizando austeridade e, posteriormente, em reformas redutoras de titularidades. A mudança de atitude chegou a afetar o gasto que, se cresceu como um todo na década de 1980, acabou experimentando uma queda entre os anos de 1983 e 1989 
(Eurostat, 1996 apud Pierson, 1998). Ademais, é preciso considerar que, mesmo na ausência de retração presente de gastos, algumas das reformas, como as previdenciárias, só surtirão efeitos no futuro.

Na literatura especializada, as reformas das décadas de 1980 e 1990 foram avaliadas desigualmente. Por alguns, elas foram percebidas como adaptações funcionais do estado de bem-estar a novas circunstâncias, enquanto por outros, como remercantilização, recuo na responsabilidade pública ou mesmo perda de efetividade (Nullmeier e Kauffman, 2010). Vamos examinar as diferentes avaliações.

\section{Adaptação: Novos Riscos, Novo Welfare}

Segundo essa perspectiva, as modificações observadas no welfare state pós-anos 1970 consistiriam em adaptações funcionais a mudanças no ambiente econômico, social e político. Entre estas estariam a desindustrialização, a globalização, as novas estruturas de classe e composição das famílias, mudanças demográficas e novas relações de gênero, além de mudanças de regime político, democratização, reformas constitucionais e novos níveis de mobilização política (Nullmeier e Kauffman, 2010). Essas circunstâncias se traduziriam em novas estruturas de riscos sociais e, consequentemente, em novas oportunidades para o desenvolvimento do welfare state.

Fundamentalmente, os riscos sociais relacionados à industrialização, que justificaram a existência do estado de bem-estar do pós-guerra, teriam sido substituídos por um conjunto de novos riscos (Bonoli, 2005). A reestruturação deste decorreria de novos processos exógenos, como a crise econômica dos anos 1970 e a globalização a partir dos anos 1980 que, apesar de terem afetado a margem de manobra para políticas públicas domésticas, criaram novas necessidades em termos de proteção social (ver, por exemplo, Rodrik, 1996). Outro processo econômico transversal ao anterior seria a desindustrialização e a reestruturação do mercado de trabalho que a acompanha. Mudanças tecnológicas limitativas ao crescimento do emprego, proeminência da economia dos serviços e avanço da economia do conhecimento foram fatores que impuseram menor segurança no emprego e relações de trabalho mais precárias, requerimento de maior qualificação do trabalho, desemprego duradouro e dualidade no mercado de trabalho - riscos relativamente desconhecidos do welfare state industrial e que solicitariam respostas adaptativas de um welfare state pós-industrial (Taylor-Gooby, 2002; 
Esping-Andersen, 1999). Um terceiro subconjunto de novos riscos adviria das mudanças demográficas (destacando-se o já mencionado envelhecimento das populações) e dos novos arranjos familiares (com mais famílias uniparentais, famílias com dois trabalhadores, famílias compostas de apenas um indivíduo), os quais requereriam perfis diferenciados de proteção e crescente individualização do welfare. Os novos riscos estimulariam adaptações na direção de um novo estado de bem-estar: o discurso segundo o qual estaria havendo uma "redução de benefícios", referenciado a uma perspectiva dos riscos da industrialização, seria insensível às novas fontes de riscos sociais a requererem proteção sob novas circunstâncias e, portanto, à expansão de benefícios em novas áreas de fato ocorrida. Essas adaptações foram, em geral, qualificadas como "recalibragem" ou "transformação" do estado de bem-estar (Pierson, 2006; Seeleib-Kaiser, 2008). Entre as novas áreas de ação estão as políticas de mercado de trabalho ativo e as políticas de conciliação da vida familiar com o trabalho.

\section{Remercantilização}

Outro tipo de análise interpreta as alterações na estrutura interna dos programas da seguridade social em resposta ao aumento da demanda (sobretudo da população idosa) menos como "adaptações funcionais" e mais como "reestruturação" com significativa perda de titularidades.

Pierson (2006), por exemplo, documenta retração de titularidades, ao longo das décadas de 1980 e 1990, no valor dos benefícios (queda no valor real), no acesso aos programas (que tem se tornado mais restritivo, com teste de meios mais utilizados e critérios mais duros de elegibilidade) e na introdução de formas de copagamento (redução dos subsídios governamentais aos provedores de serviço, maior utilização de testes de ativos e de cocontribuições). Adicionalmente, a modificação na estrutura da tributação, com o crescente apoio em impostos indiretos e o aumento das contribuições dos empregados, caracterizaria o período recente como menos universalista e redistributivo. $\mathrm{O}$ autor compilou as seguintes alterações em titularidades na área da OECD, ocorridas ao longo dos anos 1990 (Quadro 1).

Na mesma linha, Korpi e Palme (2007, apud Nullmeier e Kauffman, 2010) constataram redução das taxas médias de reposição de rendimentos nos diferentes ramos da seguridade social. O início do proces- 
Quadro 1

Alterações em Benefícios na Área da OECD - Anos 1990

\begin{tabular}{|c|c|c|}
\hline Tipo de Benefício & Mudança & Países \\
\hline \multirow{3}{*}{ Aposentadorias } & Aumento da idade para aposentar-se & RU, NZ, IT, JP \\
\hline & $\begin{array}{l}\text { Extensão do período para requerer apo- } \\
\text { sentadoria plena }\end{array}$ & FR, PT, IR, FI \\
\hline & $\begin{array}{l}\text { Redução da base para ajuste dos benefí- } \\
\text { cios com base na inflação }\end{array}$ & RU, FR, ES \\
\hline \multirow[b]{3}{*}{ Incapacidade } & Teste de meios para a aposentadoria & Áustria, DN, AUS \\
\hline & Testes mais estritos de incapacidade & RU, EUA, HO, NO \\
\hline & $\begin{array}{l}\text { Novos limites de duração, benefícios re- } \\
\text { duzidos }\end{array}$ & RU, EUA, HO \\
\hline \multirow{2}{*}{ Desemprego } & Redução na duração dos benefícios & BE, RU, DN, EUA \\
\hline & Redução no nível dos benefícios & AL, IR, NZ, Suíça \\
\hline \multirow[b]{2}{*}{ Benefícios para famílias } & Elegibilidade reduzida & $\mathrm{HO}, \mathrm{RU}, \mathrm{BE}$ \\
\hline & $\begin{array}{l}\text { Valor real declinante ou elegibilidade de- } \\
\text { crescente }\end{array}$ & RU, ES, HO \\
\hline
\end{tabular}

Fonte: Pierson (2006).

so de recuo foi identificado em 1995: 46 entre 54 medidas (para 18 países em três tipos de benefício: auxílio-doença, seguro-desemprego, aposentadorias) tiveram valores reais em 1995 abaixo dos níveis de pico. Na maioria dos casos, os anos 1970 se revelaram parte do período de expansão. A medida utilizada - uma combinação de estrutura dos programas e nível de benefícios - permite corroborar a hipótese de alguma retração já nos anos 1980 (Nullmeier e Kauffman, 2010). Os indicadores de ausência de mudança estrutural significativa de Castles (2004), computados em termos de gastos agregados em programas, não desceram ao nível de regras de elegibilidade, valor de benefícios, condicionalidades e formas menos ortodoxas de financiamento 9 : o ajuste diante de pressões sobre o orçamento pode ter se dado a esse nível. Assim mesmo, uma redução relativa na seguridade social tinha sido captada por Castles (2004).

Contudo, outros estudos, usando o salário médio como referência para o valor dos benefícios, não observam esses recuos. Allan e Scruggs (2004), usando a metodologia de Esping-Andersen (1990), constatam uma estabilidade média dos graus de desmercantilização ${ }^{10}$ desses mesmos programas, no mesmo período; Starke et alii, 2008, desagregando os programas, encontram aumento do grau de desmercantilização das aposentadorias, redução no que se refere a auxílio-doença e es- 
tabilidade no que diz respeito ao seguro-desemprego, entre 1980 e 2002, com metodologia semelhante à utilizada por Allan e Scruggs (2004).

Ao que parece, a questão de se teria ou não havido uma reversão da universalização da seguridade social, característica da fase de formação e expansão do welfare state em direção a crescentes securitização e residualização careceria ainda de verificação adicional. De todo modo, discordando da avaliação pessimista de Pierson e outros, Nullmeier e Kaufmann (2010) argumentam que as evidências conhecidas de remercantilização singularizariam o aspecto de "seguridade social" do estado de bem-estar, não contemplando outras áreas de expansão como, por exemplo, as políticas ativas de mercado de trabalho ${ }^{11}$ e de investimento social ${ }^{12}$. A avaliação final dependeria então da incorporação dessas novas políticas e, portanto, da adoção de outra perspectiva sobre o welfare state.

\section{Privatização}

A modificação da clivagem público-privada constituiria o elemento definidor das transformações ocorridas nas últimas décadas, na opinião de vários autores: a primeira fase do welfare state teria sido marcada pela centralidade da provisão pública, enquanto a nova fase se caracterizaria pelo avanço da provisão privada. $\mathrm{O}$ avanço da privatização do bem-estar é documentado nos diferentes regimes de bem-estar (Palier, 2010; Kautto, 2010).

Nullmeier e Kaufmann (2010) observam que essa avaliação subestima a importância do financiamento público e dos subsídios e renúncias tributárias na sustentação de boa parte da provisão privada. Nesse sentido, os autores recomendam uma revisão da avaliação convencional de que haveria um nível diminuto de responsabilidade pública na provisão de bem-estar social norte-americana, dada a ocorrência disseminada de financiamento público ao gasto privado via deduções e isenções fiscais, aspecto que tem recebido atenção crescente nos últimos anos (Skocpol, 1995; Esping-Andersen, 1999, 2009; Hacker, 2003). De fato, caso fosse considerado o gasto social líquido (gasto social bruto depois do fisco), e não apenas o gasto bruto como normalmente se faz, a diferença entre os EUA e a Suécia em termos de envolvimento público no welfare praticamente desapareceria ( $31 \%$ versus $27 \%$ do PIB, no lugar de $37 \%$ versus $17,4 \%)^{13}$ (OECD, 2007). 
Porém, essa observação não é satisfatória, tendo em vista o baixo grau de redistribuição do gasto social líquido americano e a alta progressividade do gasto bruto sueco. Teremos que retornar a esse ponto, o que faremos na seção seguinte.

\section{Perda de Efetividade: Mais Desigualdade e Pobreza?}

A partir dos anos 1980, as desigualdades, que vinham declinando ao longo do pós-guerra, começam a aumentar: o relatório da OECD (2008) documenta o crescimento da desigualdade de renda (da renda de mercado e da renda disponível, isto é, os rendimentos de mercado após impostos diretos e transferências governamentais), entre 1980 e meados dos anos 2000. Podemos nos perguntar se o welfare state teria falhado em promover redistribuição.

O nível de redistribuição resultante do estado de bem-estar é convencionalmente estimado como a diferença entre a desigualdade na distribuição da renda de mercado e a desigualdade na distribuição da renda disponível, e essas desigualdades são normalmente estimadas pelo coeficiente de Gini. O que se observa no relatório é que, em quase todos os países da área, o welfare state seguiu reduzindo a desigualdade de renda ${ }^{14}$. Cálculos de Goudswaard e Caminada (2010), com base nos dados da OECD (2008), mostram que o impacto redistributivo médio do welfare state seguiu bastante elevado: uma redução de 33\% (ou 15 pontos) no coeficiente de Gini - maior na Suécia, na Dinamarca e na Bélgica (mais de $44 \%$ ); menor nos EUA (17\%) e na Coreia (8\%, a partir de uma base relativamente baixa).

Uma análise por períodos revela que, entre meados dos anos 1980 e meados dos anos 1990, o aumento observado da desigualdade foi claramente puxado pela desigualdade da renda de mercado e apenas parcialmente compensado por transferências públicas e impostos sobre as famílias. Porém, no segundo período, entre meados dos anos 1990 e meados dos anos 2000, ocorreram dois movimentos: houve uma redução inicial no crescimento da desigualdade da renda de mercado e, posteriormente, uma reversão para o mesmo padrão observado no primeiro período, com a desigualdade da renda de mercado aumentando e sendo parcialmente compensada por redistribuição, porém, a um ritmo menor. O relatório faz duas observações importantes em relação ao welfare state nesse segundo período: ele nota que a estabilização da desigualdade da renda de mercado no início do período pode ser atribuí- 
da ao welfare state ${ }^{15}$ - nesse caso, ao sucesso de políticas de ativação dos beneficiários na melhoria dos rendimentos de mercado -, mas que o aumento da desigualdade da renda disponível ao fim do período também pode ser atribuído a transferências e impostos menos redistributivos (OECD, 2008:31). Nesse caso, duas tendências recentes das políticas sociais estariam envolvidas: as políticas de ativação (com impacto provável de redução da desigualdade) e o welfare fiscal e ocupacional ${ }^{16}$ (com impacto provável de aumento da desigualdade).

Com relação à pobreza, Scruggs e Allan (2004), analisando o período entre os anos 1980 e o final dos anos 1990, concluem que a pobreza relativa, medida como a proporção de pessoas abaixo da linha de pobreza equivalente a $40 \%$ da renda mediana, aumentou em metade dos países da área da OECD (em 7\% na área anglo-saxã e em 4\% na não anglo-saxã) e estagnou, ou mesmo recuou levemente, na outra metade. A linha de corte de $40 \%$ da renda mediana foi estipulada para igualar à linha de pobreza dos Estados Unidos. Complementarmente, Fritzell e Ritakallio (2010) observam que, se a pobreza relativa, em termos de renda de mercado, aumentou nos países da Europa ocidental entre 1980 e 2000, o welfare state em suas várias dimensões foi crucial para a sua redução em termos de renda disponível, tendo realizado um esforço de redução maior em 2000 (56,2\%) do que em 1980 (54,3\%).

Porém, a pobreza relativa pode ser vista mais propriamente como um indicador de desigualdade ${ }^{17}$, exprimindo, na realidade, distintas condições de bem-estar e privação em países mais ou menos ricos. Se adotarmos o indicador mais geralmente aceito, a pobreza absoluta, observaremos um declínio em quase todos os países (a exceção é a Austrália). Este em parte teria sido promovido pelo boom econômico dos anos 1990. Todavia, segundo os autores, esse não teria sido o fator decisivo, pois, pelo menos na Europa, a queda maior ocorreu ao longo dos anos 1980 de crescimento lento. E, nos anos 1990, apesar do crescimento econômico ter sido mais lento na Europa que nos EUA, a maioria dos países europeus já registrava níveis de pobreza absoluta inferiores aos norte-americanos. A influência do welfare state nesse resultado foi diretamente observada. Tendo encontrado evidência da efetividade das políticas sociais (e dos partidos de esquerda que as implementaram e/ou expandiram) mais generosas da Europa, os autores notam que mais que o mero montante do gasto social foi a estrutura da proteção social o aspecto mais importante para explicar a redução da pobreza. Confirmando esses resultados, Kenworthy (2010) mostra que a pobre- 
za absoluta diminuiu mais em países com welfare states mais redistributivos, e que foram estes os elos de transmissão do crescimento econômico à redução da pobreza.

$$
* * *
$$

Ao lado das mudanças qualitativas observadas na área da OECD, outro desenvolvimento significativo pós-anos 1980 é o progressivo catching up social de países fora da área da OECD, muitos com resultados expressivos em termos de redução de desigualdades e pobreza. De fato, o estado de bem-estar começa a se expandir no Leste Asiático a partir de 1945, mas o crescimento se acelera justamente a partir dos anos 1980, em muitos casos coincidindo com a redemocratização dos países (Haggard e Kaufman, 2008; Nullmeier e Kaufmann, 2010; Peng e Wong, 2010). Na América Latina, cuja redemocratização ocorreu no mesmo período, mas que se encontrava então limitada pelos efeitos da crise da dívida, é a partir dos anos 1990 e, decididamente, dos anos 2000, que o welfare state se expande (Haggard e Kaufman, 2008; Cornia, 2010; Kerstenetzky, 2010), mimetizando, como a Ásia, as fases de desenvolvimento europeias. Também na Europa do Leste, após uma fase de recuo da proteção social em seguida ao fim do socialismo, vários países começam a reestruturar seus arranjos de bem-estar pós-anos 1990. Enquanto modelos residualistas ganham difusão nos estados bálticos, na Bulgária, na Romênia e na Eslováquia (cf. Cook, 2010), algumas experiências como a da Eslovênia e a da República Tcheca sugerem avanços na direção da universalização de direitos sociais (Cook, 2010), ao mesmo tempo que os gastos sociais proporcionais da República Tcheca, Hungria e Polônia já superam a média da OECD (Seeleib-Kaiser, 2008).

$$
\text { *** }
$$

Em suma, integrando-se os cinco pontos levantados nesta seção, observamos que, para além da difusão global de sistemas de proteção social que ocorre justamente no período de "crise" ou "retração" do welfare state, as transformações recentes parecem indicar que o welfare state tradicional, centrado na seguridade, estaria lentamente se adaptando para responder aos novos riscos sociais, com a expansão relativa e absoluta dos serviços de saúde e de cuidados e a retração relativa (mas não absoluta) de gastos em seguridade (cf. Tabela 1, com base em Castles, 2004). Nesse processo estaria possivelmente havendo ainda uma troca de aprofundamento vertical por expansão horizontal de titulari- 
dades para atender a uma clientela crescente e individualizada (uma "remercantilização" relativa) e um aumento na penetração do setor privado publicamente incentivado (privatização) - aspectos aos quais retornaremos na próxima seção. Do ponto de vista da efetividade, as esperadas reduções das desigualdades na distribuição da renda disponível, não tanto dos níveis de pobreza relativa quanto dos de pobreza absoluta, seguem sendo observadas. Porém, uma dúvida paira sobre essas mudanças: estaria o welfare state assim reestruturado reduzindo menos a desigualdade e a pobreza do que se poderia esperar? Ou seja, que há uma redução real não parece haver dúvida, mas será que a nova configuração diminui o potencial de redução de desigualdade dos recursos redistribuídos pelo welfare state? Há certa evidência disso, como veremos.

\section{COMO AVALIAR AS TRANSFORMAÇÕES?}

Nesta seção, procuraremos avaliar diretamente os efeitos redistributivos das transformações qualitativas observadas. Como vimos, ainda que os números referentes a gastos (totais, médias, composição) não revelem diminuição da responsabilidade pública em termos financeiros, reformas na direção de maior provisão e governança privadas e remercantilização ocorreram em todos os regimes. O receio é que essas reformas possam reduzir o efeito compensatório do estado de bem-estar sobre a desigualdade econômica produzida pelo mercado.

Seeleib-Keiser (2008) sugere que as transformações recentes sejam avaliadas considerando-se dois conjuntos de dimensões: de um lado, diferenciando-se discursos, instituições e resultados, de outro, atentando-se para a variedade de formas de intervenção pública: provisão, financiamento (gasto e tributação) e regulação.

No nível do primeiro conjunto de dimensões, há notável uniformidade de discursos e instituições, nem tanto de resultados. O discurso em favor da participação privada na provisão de bem-estar é cada vez mais influente, dado o aumento da demanda e as restrições à capacidade de os governos intensificarem a tributação. Consequentemente, mais reformas respondendo explicitamente a essas pressões são observadas: sistemas previdenciários de múltiplos pilares, provisão privada de serviços, políticas ativas de mercado de trabalho. Porém, a diversidade entre os países no que se refere a resultados sugere a persistência de re- 
gimes de bem-estar e, portanto, diferenças reais em políticas específicas e/ou nas combinações entre elas.

O segundo conjunto de dimensões capta a multiplicidade de formas de responsabilidade pública. Na fase da expansão do pós-guerra, a provisão pública foi a forma dominante; na atual fase, ao lado do crescente envolvimento privado na provisão se nota um maior envolvimento do Estado na regulação das atividades, no chamado welfare fiscal (gastos tributários) e na compra de serviços ao setor privado. Registra-se, em paralelo, a expansão da provisão pública em setores não tradicionais, como, por exemplo, as políticas de conciliação da vida familiar com o trabalho. Na média, os níveis "nominais" de responsabilização pública não teriam diminuído, considerando-se provisão-regulação-financiamento e respeitando-se as diferenças entre os regimes.

E quanto aos níveis "reais"? Enquanto o aprofundamento da função "regulação" pode ter em vários casos ampliado o acesso, a cobertura e mesmo a efetividade dos serviços (por exemplo, a redução do tempo de espera no National Health Service britânico com as parcerias público-privadas, a incorporação em vários países de trabalhadores "não padrão" na seguridade), a intensificação do welfare fiscal e o encorajamento da provisão social privada (acesso a serviços e seguridade por meio do emprego, ou créditos tributários para a aquisição de ambos no setor privado ou subsídios a este para a provisão de serviços e seguridade) devem ter gerado problemas de dualidade de bem-estar. Como já mencionado, países que utilizam preferencialmente esse mecanismo, como os EUA, apresentam um gasto social líquido bem mais elevado que o gasto social bruto, porém, têm maior desigualdade nos níveis de bem-estar (Castles, 2004; Seeleib-Kaiser, 2008; Esping-Andersen, 2009).

Para nomear esses arranjos contemporâneos de bem-estar, SeeleibKaiser (2008) sugere o termo "sistema de bem-estar": "um arranjo social que assegura contra riscos sociais de um modo coletivo, altamente regulado e/ou redistributivo, com um nível de certeza relativamente alto em relação aos benefícios futuros" (idem, 11). Em um sistema desse tipo, a política social pode em princípio ser provida por atores públicos e/ou privados sem necessariamente violar as fronteiras do domínio público, porque o motivo "lucro" estaria subordinado ${ }^{18}$ (ibidem). Seeleib-Kaiser sugere então que a atenção se desloque da estrutura de provisão para as formas de monitoramento e prestação de contas, 
e, portanto, para a governança democrática, legal e profissional (e não de mercado ou meramente reputacional) desses sistemas.

Voltaremos à questão do "domínio público", e, portanto, da formação de um juízo normativo que justifique a maior participação privada na provisão de welfare, na última seção. No momento, para entendermos a extensão e o impacto da privatização das políticas sociais na nova fase do welfare state, procederemos em duas etapas. Inicialmente, analisaremos políticas nucleares do estado de bem-estar que sofreram reformas recentes - aposentadorias e pensões, emprego e desemprego, conciliação da família com o trabalho e saúde - para observar mudanças em instituições e/ou discursos, nos modos de intervenção pública e, na medida do possível, também nos resultados em termos de redistribuição. Em seguida, apresentaremos uma avaliação mais abrangente da adoção de políticas sociais privadas na área da OECD, a fim de avaliar se as tendências privatizantes estariam representando uma perda relativa em termos de redução das desigualdades.

Começaremos pelas políticas de aposentadoria que foram as que sofreram as reformas mais extensas. Muitos países se deslocaram de sistemas públicos para sistemas de múltiplos pilares e alteraram regras de elegibilidade (Seeleib-Kaiser, 2008; Pierson, 1998; Korpi e Palme, 2007, apud Nullmeier e Kauffman, 2010). A maioria dos países da área da OECD aumentou a participação privada, seja por meio da redução de benefícios públicos ou do encorajamento à adesão a planos privados e ocupacionais, através de medidas regulatórias e/ou incentivos tributários. Enquanto discursos e instituições sinalizaram privatização e remercantilização, a intervenção pública deslocou-se em direção ao financiamento (indireto via renúncia fiscal, ou direto via subsídios) e à regulação (Seeleib-Kaiser, 2008; Pierson, 1998, 2006). Em termos de resultados, as reformas nas aposentadorias representaram proteção mais fraca para quem estava fora do mercado de trabalho, menor redistribuição e maior incerteza quanto aos níveis futuros dos benefícios. Por outro lado, elas envolveram, em alguns casos, a inclusão de empregados não padrão (trabalhadores temporários, trabalhadores em tempo parcial, camponeses) na cobertura da seguridade social (Seeleib-Kaiser, 2008), o que implicou alteração do marco regulatório e ampliação da provisão pública.

Uma ideia dos efeitos de longo prazo de tais reformas é sugerida pelos resultados da simulação para o ano de 2050, reportada por Seeleib- 
Kaiser (2008), que incluiu o Reino Unido, a Alemanha, a Itália, a Holanda, a Polônia e a Suíça. Conquanto todos esses países tenham se movido para sistemas multipilares, apenas os sistemas de pensão público-privados introduzidos na Holanda e na Suíça proveram um patamar de renda próximo ao nível definido de inclusão social. Estes países possuíam os níveis mais elevados de provisão pública (Holanda) ou a cobertura mais extensiva de provisão ocupacional privada (Suíça). A Dinamarca, que não foi incluída na simulação, mas sofreu mudanças importantes nas aposentadorias em direção a pensões privadas (governadas por negociação coletiva e cobrindo quase todos os empregados), deve se aproximar do resultado obtido pela Suíça, considerando-se ainda que os seus idosos pobres recebem assistência generosa, $o$ que faz com que o país tenha as mais baixas taxas de pobreza entre idosos entre os países da OECD. Os casos excepcionais da Suíça, Holanda e Dinamarca, em contraste com os demais países, ilustram o fato de a simples afinação em termos de discursos e (aparentemente também em) instituições diretamente envolvidas não ser suficiente para explicar resultados, sendo necessário observar interações entre diferentes instituições (incluindo a existência de negociação coletiva e supervisão pública da negociação) e as práticas e normas sociais que as animam (por exemplo, a norma de garantir a segurança na velhice). Em outro estudo, Mann (2009) observou diretamente efeitos regressivos dos incentivos tributários às aposentadorias privadas no Reino Unido, onde $60 \%$ do montante dos incentivos se destina a pessoas nas faixas mais elevadas de tributação, e nos EUA, que terão devotado cerca de 300 bilhões de dólares em incentivos a aposentadorias privadas no período 2005-2010 às mesmas faixas.

As políticas de emprego e desemprego testemunharam ao mesmo tempo um aumento do envolvimento público direto (provisão) e certa remercantilização. Estes aspectos ambíguos se fizeram presentes na combinação de um seguro-desemprego mais restritivo com políticas ativas de mercado de trabalho - o estreitamento de condicionalidades e redução de benefícios convivendo com a ampliação da oferta de serviços públicos de mercado de trabalho e de licenças (licença-paternidade e licença de emergência durante a doença de um filho). Alguns países, como a Inglaterra e a Holanda, usaram programas de incapacidade para proteger grupos vulneráveis, dessa forma compensando a redução da responsabilidade pública nos benefícios para os trabalhadores desempregados ${ }^{19}$. Esses programas variaram muito em desenho. Em alguns países, a essas reformas somou-se a flexibilização do merca- 
do de trabalho. A Dinamarca, por exemplo, além de flexibilizar seu mercado de trabalho, reduziu a taxa de reposição para o trabalhador de produção médio e reforçou condicionalidades, porém, para os grupos de mais baixa remuneração, sobre os quais recai mais pesadamente o desemprego, ainda provê benefícios muito generosos (SeeleibKaiser, 2008). Ironicamente, as reformas que visaram aumentar a participação no mercado de trabalho introduzindo condicionalidades no recebimento do seguro-desemprego foram mais bem sucedidas nos países em que o Estado era a instituição mais importante na provisão do seguro-desemprego (como Inglaterra e Dinamarca) do que em países onde este é administrado pelos chamados "parceiros sociais" (sindicatos e associações de classe). As mudanças foram mais difíceis e limitadas na Bélgica, França e Alemanha, países nos quais os parceiros sociais têm maior peso na governança do sistema. O mesmo ocorreu com os benefícios de incapacidade, com o deslocamento da ênfase compensatória típica desses benefícios para a ênfase em ativação (recebimento do benefício condicional a algum tipo de atividade por parte do beneficiário) sendo mais bem-sucedido em países, como a Holanda e a Suécia, nos quais o Estado já detinha considerável influência na administração dos benefícios em detrimento dos parceiros sociais.

Na média, segundo as estimativas de Goudswaard e Caminada (2010), as políticas de mercado de trabalho ativo tiveram um efeito positivo e significativo sobre a redistribuição (meados de 2000). Há, porém, grande variação nacional e regional. Ademais, de um modo geral, os países nórdicos, que usaram mais consistentemente essas políticas, tiveram taxas de desemprego relativamente baixas dentro da área da OECD no período recente (até 2008).

Em termos de políticas de conciliação da vida familiar com o trabalho, a maioria dos países do bloco aumentou a responsabilidade pública na provisão e financiamento públicos de serviços de cuidados a crianças e idosos, ao mesmo tempo em que estimulou elementos de competição de mercado dentro dos serviços de provisão pública e encorajou algum nível de envolvimento do setor privado. Igualmente, há variação nacional importante. O Reino Unido, por exemplo, tem adotado essas políticas visando o emprego feminino, porém, não com a orientação de equidade de gênero (Seeleib-Kaiser, 2008) que é observada na Dinamarca, país que tem os serviços de cuidado mais avançados da área da OECD. A análise empírica dos impactos redistributivos de algumas dessas políticas, realizada por Goudswaard e Caminada (2010) con- 
cluiu que programas públicos para pessoas idosas (especialmente) e para famílias (em menor medida) exerceram, em média, efeito positivo e significativo sobre a redistribuição (meados dos anos 2000).

Finalmente, em relação aos sistemas de saúde, não se observou uma tendência unidimensional de privatização nos países da OECD, porém, na média, embora tenha ocorrido uma expansão da provisão pública (sobretudo por conta do catching up dos países do sul da Europa), a provisão privada cresceu mais rapidamente. Houve um processo de hibridização dos sistemas de saúde, envolvendo principalmente o Reino Unido, a Alemanha e os EUA. A participação do Estado se expandiu no que se refere à regulação e ao financiamento. Cálculos preliminares da OECD (2008) para meados de 2000 indicam que os gastos com serviços públicos de saúde reduzem ligeiramente a desigualdade em todos os países da OECD ${ }^{20}$.

Em suma, no que diz respeito aos gastos tradicionais em seguridade e saúde, ainda que tenha havido aumento do acesso à seguridade de trabalhadores não padrão, a participação relativa estatal parece ter se retraído no aspecto provisão e se dilatado nas dimensões regulação e financiamento, especialmente tributário. Por outro lado, novas fontes de bem-estar foram "desprivatizadas" ou "desfamiliarizadas", com a provisão pública de serviços de cuidado e de programas de ativação (acompanhando uma remercantilização associada a contrapartidas para a obtenção do seguro-desemprego). Além disso, houve modificação nas estruturas de governança, com a convivência de princípios de mercado (competição/escolha e gestão eficiente), na provisão pública, com princípios de prestação de contas, típicos da gestão pública, na provisão de serviços privados - combinações observadas em sistemas de saúde de países de diferentes regimes (Rothgang et alii, 2006). De um modo geral, à exceção dos programas de aposentadoria, esses mixes público-privados foram individualmente compatíveis com reduções da desigualdade na distribuição de renda.

Tendo brevemente descrito e avaliado reformas recentes em programas centrais do welfare state, procederemos à questão de serem ou não as novas tendências tão redistributivas quanto poderiam ser. Nossa questão não é mais, portanto, meramente saber se reformas em programas específicos foram regressivas ou não, mas se elas alteraram o potencial de redistribuição do estado de bem-estar, dado que sua institu- 
cionalidade tem sido modificada para acomodar uma maior participação privada.

O relatório da OECD (2008) indicou, como vimos na seção anterior, uma redução da redistributividade das transferências públicas no período recente. Para uma segunda aproximação do problema, utilizaremos evidências sistematizadas no estudo de Goudswaard e Caminada (2010) para 25 países, com base nos dados disponibilizados no relatório OECD (2008), sobre o potencial redistributivo de políticas sociais públicas e privadas. Os autores constataram que políticas sociais privadas $^{21}$ têm uma relação negativa (pequena, porém significativa) e as políticas sociais públicas, uma correlação positiva, forte e significativa com a redistribuição ${ }^{22}$. Eles concluíram que a escolha do peso relativo da provisão pública e privada de proteção social afeta o impacto redistributivo do estado de bem-estar (Goudswaard e Caminada, 2010:1-2). A causa provável é que programas privados não contêm as medidas de solidariedade em matéria de benefícios que são típicas dos programas públicos (idem:3).

Em meados dos anos 2000, os gastos sociais privados representavam em média menos de $15 \%$ dos gastos totais, com grande variação entre os países (9\% na Suécia e na Dinamarca, $40 \%$ nos EUA, acima de 25\% no Canadá, Coreia, Países Baixos, Suíça e Reino Unido). Porém, esses gastos vêm aumentando desde 1985, em seis países ele cresceu mais do que o gasto público (o maior incremento foi observado na Bélgica, no Canadá, no Japão, nos Países Baixos, na Suíça e nos EUA) [Goudswaard e Caminada, 2010]. Esses gastos são em geral voluntários e se valem de deduções fiscais, e podem até ter impactos redistributivos, porém, de um modo geral, as vantagens fiscais têm impacto regressivo.

Os autores desagregaram a análise para observar o efeito ao nível dos programas: os mais redistributivos foram os programas públicos para pessoas idosas e para o mercado de trabalho ativo; os mais concentradores foram justamente as aposentadorias privadas (relação negativa, mas a um nível de significância de 10\%). Os autores examinaram tanto o gasto social bruto quanto o líquido, e as mesmas relações agregadas foram encontradas.

Com base nessa evidência, pode-se inferir que a divisão público-privada na provisão importa do ponto de vista do potencial redistributivo do welfare state ${ }^{23}$. 


\section{COMENTÁRIOS FINAIS}

Enquanto nos países menos desenvolvidos há uma onda de difusão de instituições de bem-estar social, em boa medida comparável com a onda anterior de expansão na Europa e América do Norte, indicando a centralidade do welfare state nos processos de desenvolvimento econômico, especialmente quando conduzidos democraticamente, nos países desenvolvidos, o estado de bem-estar segue vigoroso. De fato, em nenhum dos sentidos apresentados na seção 1 pode o período contemporâneo ser inequivocamente caracterizado como uma crise, tendo-se em mente os vários indicadores de gasto social, que seguiram crescendo nas décadas de redução da atividade econômica a um ritmo superior ao do crescimento do produto. Esse ritmo de crescimento foi, porém, mais lento do que o observado no pós-guerra, indicando que possivelmente o welfare state maduro tenha "crescido aos limites". O período contemporâneo deve ser, não obstante, visto como uma nova fase do estado de bem-estar, em que transformações qualitativas ocorreram menos intensamente no desenho macro e mais extensamente na arquitetura micro dos programas, na qual residem regras de inclusão e generosidade - e uma redivisão público-privada se delineia.

Ainda que as mudanças não caracterizem alterações radicais, observa-se um incremental deslocamento de um welfare de seguridade em direção a um welfare de serviços. Ainda, conquanto as reformas não tenham representado recuo na responsabilidade pública como um todo e nas áreas novas ela tenha comparecido como provisão direta, nas áreas tradicionais, a responsabilidade pública diminuiu enquanto provisão direta e aumentou como regulação e financiamento.

Essa modificação nas funções do Estado não é inocente distributivamente e pode ser responsável por uma redução da redistributividade do welfare state em tempos recentes: a maior utilização de políticas sociais privadas, especialmente em seguridade e saúde, as duas maiores rubricas do gasto social, pode estar abrigando transferências menos redistributivas (típicas do welfare fiscal e ocupacional). Por outro lado, o acento em serviços - ocorrendo neste setor uma verdadeira publicização de aspectos privados do bem-estar, como o cuidado de idosos e crianças pequenas e a preparação para o (e inserção no) mercado de trabalho - pode estar refletindo a preocupação com as funções de ativação do estado de bem-estar, isto é, com a capacidade que suas instituições têm de contribuir para relaxar suas próprias restrições financeiras via 
aumento da participação da população no mercado de trabalho. Estas iniciativas sinalizariam, positivamente, uma resposta robusta das instituições de bem-estar social à desnaturalização da "sociedade do crescimento" que sustentou o consenso do pós-guerra.

Avançar na direção de avaliar se nesse processo o welfare state negociou sua alma requer ir além de considerações econômico-financeiras e introduzir um marco normativo. Uma categoria analítica sugerida por David Marquand (2004) pode nos ajudar a avançar na separação do joio do trigo. Esta é a categoria "domínio público". Seeleib-Kaiser (2008) havia tentado distinguir um domínio público como aquele em que o motivo "lucro" é subordinado. Recorrendo à fonte dessa ideia, recuperamos o conceito de Marquand: domínio público se refere ao reino da cidadania, isto é, às dimensões e atividades da vida social reguladas por normas como "equidade" e "serviço" (e não, por exemplo, "lucro" e "lealdades") voltadas para a promoção do interesse comum. Esse se distingue, portanto, de um domínio privado, onde prevalecem o interesse privado ou as relações afetivas e de reciprocidade ou lealdade. O domínio público não é um setor separado - por exemplo, o setor público - mas uma normatividade (equidade e serviço) que atravessa diferentes setores. O domínio público pode operar no setor privado (o servidor pode estar imbuído dos motivos equidade e serviço), do mesmo modo que as normas do domínio privado podem estar operando - deslocada e erroneamente - no setor público (o servidor pode estar imbuído da busca de vantagens próprias ou da busca de eficiência em detrimento de equidade ou qualidade).

Essa reflexão tem incidência sobre o campo do bem-estar social. As razões para as reformas - dado que reconhecemos este como o campo da cidadania - tem que estar contempladas no domínio público: o espírito do serviço e da equidade. Se as reformas, por exemplo, aumentam o acesso, mas conduzem à segregação ou aumentam a insegurança, elas violam o domínio público. A subordinação da motivação lucro via regulação, como sugerido por Seeleib-Kaiser, é um aspecto importante, mas não suficiente para caracterizarmos o domínio público do bem-estar. Em termos mais amplos, sugere-se atenção aos seguintes aspectos de um mix público-privado compatível com o domínio público:

1) princípios: maior nível de certeza possível, maior nível de adequação possível, maior nível de equidade possível, maior nível de cobertura possível; 
2) processos: máxima transparência e prestação de contas, oportunidade máxima para participação e deliberação por parte dos "beneficiários";

3) resultados: expansão equitativa de capacitações (como liberdade real). Pobreza e desigualdade seriam alguns indicadores, mas também a equidade nos padrões de bem-estar obtidos por meio da intervenção.

Em suma, quaisquer que sejam as eventuais vantagens sociais das políticas privadas, sua adoção, dada sua menor capacidade redistributiva e o maior risco que comportam de segregação e segmentação do bem-estar, deveria ser limitada pela observância dos parâmetros do domínio público.

(Recebido para publicação em dezembro de 2011)

(Reapresentado em março de 2012)

(Aprovado para publicação em maio de 2012) 


\section{NOTAS}

1. Entre elas cabe mencionar as mudanças nas relações de troca internacionais e o fim do sistema de Bretton Woods de taxas de câmbio fixas.

2. A palavra inglesa entitlements, referindo-se, no caso presente, a direitos sociais exigíveis juridicamente, foi traduzida como "titularidades" ao longo do texto. Agradeço a sugestão de um dos pareceristas anônimos.

3. Aqui estão incluídos os principais programas de transferência de renda, como aposentadorias e pensões, seguro-desemprego, auxílio-doença e incapacidade, auxílio por acidente de trabalho.

4. Conceito sociológico que se refere às oportunidades socialmente disponíveis aos indivíduos para melhorar a qualidade de suas vidas. Analiticamente, é um conceito probabilístico que permite estimar razoavelmente quais serão as perspectivas econômicas futuras dos indivíduos a partir de sua situação social.

5. Contudo, a dificuldade com essa literatura é a sensibilidade dos resultados às variáveis escolhidas para representar o welfare state e a globalização.

6. Uma referência clássica para a discussão de regimes de bem-estar é Esping-Andersen (1990), que identifica os regimes de estado de bem-estar liberal, conservador e social-democrata, com instituições, políticas e resultados peculiares. Em outro trabalho (Kerstenetzky, 2012), trato da resistência diferenciada de cada regime aos "novos tempos", pós-anos dourados. Por exemplo, o regime conservador tende a desenvolver resistência corporativa a reformas nas políticas sociais.

7. O grau de transformação estrutural é calculado como 100 menos (100 vezes o $R^{2}$ ajustado, obtido ao se regredir os valores dos componentes do gasto social para um dado país em 1998, medidos como percentagens do PIB, sobre os valores para este país em 1980). O tamanho da redução é calculado como a soma dos cortes em componentes de um dado gasto social agregado em 1998, medida como percentagem do gasto nesta rubrica em 1980 (Castles, 2004).

8. A tipologia de Castles guarda semelhança com a proposta por Esping-Andersen (1990), em termos das características institucionais de cada família/regime, a diferença mais notável sendo a diferenciação da Europa Mediterrânea, que na tipologia de Esping-Andersen (por ele revisitada em Esping-Andersen, 1999) é incorporada ao regime conservador.

9. Porém, igualmente, não contabilizaram gastos com políticas ativas de mercado de trabalho, que se expandiram no período.

10. Grau em que os benefícios governamentais substituem os rendimentos de mercado.

11. Políticas voltadas para a inserção dos beneficiários no mercado de trabalho.

12. Por exemplo, as políticas voltadas para o desenvolvimento infantil (cf. EspingAndersen, 2009) e, de um modo geral, a ênfase no gasto social como investimento, com um retorno econômico positivo esperado.

13. Tipicamente, os EUA não tributam transferências sociais e recorrem significativamente ao chamado gasto tributário (deduções e subsídios fiscais), enquanto a Suécia pouco recorre a gasto tributário e, por outro lado, tributa todas as transferências sociais, com exceção das prestações familiares.

14. Apenas na Nova Zelândia, a desigualdade pós-redistribuição aumentou. 
15. Esping-Andersen e Myles (2009) observam que o welfare state tem efeitos importantes também na distribuição da renda de mercado, por vários meios. Não apenas ele afeta os recursos que permitirão a geração de renda (educação, saúde, programas de treinamento, serviços de cuidado), como gera uma situação de renda de mercado zero para um grande número de pessoas (aposentados, pensionistas, recebedores de auxílio-maternidade etc.), além de afetar de um modo geral o comportamento econômico dos indivíduos.

16. No welfare fiscal, a provisão de bem-estar é feita por meio de incentivos tributários, como renúncias fiscais e subsídios, enquanto no welfare ocupacional, a provisão é via a relação de emprego, normalmente também tributariamente incentivada.

17. Agradeço a observação a José Antonio Ocampo.

18. Segundo Seeleib-Kaiser (2008), exemplo de provisão privada dentro do domínio público é o sistema Ghent de seguro-desemprego, isto é, sistemas de benefícios ocupacionais relacionados aos ganhos em vários países da Europa, que não são providos nem pelo Estado nem por empresas orientadas por lucros, mas são governados por arranjos corporativos complexos.

19. Isso explica em parte as altas taxas de incapacidade e as baixas taxas de desemprego nas estatísticas desses países (cf. Kenworthy, 2004).

20. Recordando que há vários problemas conceituais e metodológicos para o cálculo do impacto sobre a desigualdade de renda de gastos em serviços.

21. Políticas sociais privadas são políticas com fins sociais (não são a contrapartida por bens e serviços, não são transferências individuais) com um "invólucro" governamental: são obrigatórias (com ou sem redistribuição) ou, quando voluntárias (contam com vantagens fiscais), são redistributivas. Exemplos de políticas privadas obrigatórias com redistribuição: auxílio-doença provido pelo empregador, benefícios acumulados a partir de contribuições obrigatórias (ex.: aposentadoria por idade); políticas privadas obrigatórias sem redistribuição: benefícios de aposentadorias sem vantagens fiscais, atuarialmente justos. Exemplos de políticas sociais privadas voluntárias: benefícios com vantagens fiscais (ex.: contas individuais de aposentadorias, benefícios de aposentadoria e saúde providos pelo empregador).

22. As políticas sociais consideradas seguem a classificação da OECD. Foram os seguintes programas (que envolvem benefícios físicos e contribuições financeiras): para pessoas de idade avançada, para sobreviventes, incapazes, assistência de saúde, famílias, mercado de trabalho ativo, desemprego, habitação, outras áreas.

23. O que não quer dizer que outros fatores não importem do ponto de vista da efetividade e do tipo de redistribuição, notadamente a diferenciação entre os regimes. 


\section{REFERÊNCIAS BIBLIOGRÁFICAS}

ALLAN, James P. e SCRUGGS, Lyle. (2004), “Political Partisanship and Welfare State Reform in Advanced Industrial Societies". American Journal of Political Science, vol. 48, no 3, pp. 496-512.

ARTS, Wil A. e GELISSEN, John. (2010), "Models of the Welfare State", in F. Castles et alii (eds.), The Oxford Handbook of the Welfare State. Oxford, Oxford University Press, pp. 569-586.

BARR, Nicholas. (2001), Welfare State as Piggy Bank: Information, Risk, Uncertainty, and the Role of the State. Oxford, Oxford University Press.

BONOLI, Giuliano. (2005), “The Politics of the New Social Policies: Providing Coverage against New Social Risks in Mature Welfare States". Policy \& Politics, vol. 33, no 3, pp. 431-449.

CASTLES, Francis G. (2004), The Future of the Welfare State - Crisis Myths and Crisis Realities. Oxford, Oxford University Press.

COOK, Linda J. (2010), "Eastern Europe and Russia”, in F. Castles et alii (eds.), The Oxford Handbook of the Welfare State. Oxford, Oxford University Press, pp. 671-688.

CORNIA, Giovanni A. (2010), “Income Distribution under Latin America's New Left Regimes". Journal of Human Development and Capability, vol. 11, no1, pp. 85-114.

CROZIER, Michel; HUNTINGTON, Samuel P. e WATANUKI, Joji. (eds.). (1975), The Crisis of Democracy: Report on the Governability of Democracies to the Trilateral Commission. New York: New York University Press.

ESPING-ANDERSEN, Gøsta. (2009), The Incomplete Revolution: Adapting to Women's New Roles. Cambridge, UK, Polity Press.

. (1999), Social Foundations of Postindustrial Economies. Oxford, Oxford University Press.

. (1990), The Three Worlds of Welfare Capitalism. New Jersey, Princeton University Press.

e MYLES, John. (2009), "Economic Inequality and the Welfare State”, in W. Salverda, B. Nolvan e T. Smeeding (eds.), The Oxford Handbook of Economic Inequality. Oxford, Oxford University Press, pp. 639-665.

FRITZELL, Johan e RITAKALLIO, Veli-Matti. (2010), “Societal Shifts and Changed Patterns of Poverty". International Journal of Social Welfare, no 19, pp. S25-S41.

GOUDSWAARD, Kees P. e CAMINADA, Koen. (2010), "The Redistributive Effect of Public and Private Social Programmes: A Cross-country Empirical Analysis". International Social Security Review, vol. 63, no 1, pp. 1-19.

HACKER, Jacob S. (2003), “Privatizing Risk without Privatizing the Welfare State: The Hidden Politics of Social Policy Retrenchment in the United States". Social Policy $\mathcal{E}$ Administration, vol. 37, no 6, pp. 639-655.

HAGGARD, Stephan e KAUFMAN, Robert R. (2008), Development, Democracy, and Welfare States: Latin America, East Asia and Eastern Europe. Princeton, NJ, Princeton University Press. 
HUBER, Evelyne e STEPHENS, John D. (2001), Development and Crisis of the Welfare State: Parties and Policies in Global Markets. Chicago, University of Chicago Press.

KAUTTO, Mikko. (2010), "The Nordic Countries", in F. Castles et alii (eds.), The Oxford Handbook of the Welfare State. Oxford, Oxford University Press, pp. 586-600.

KENWORHTY, Lane. (2010), The Politics of Helping the Poor. University of Arizona. Mimeo.

(2004), Egalitarian Capitalism: Jobs, Incomes, and Growth in Affluent Countries. New York, Russell Sage Foundation.

KERSTENETZKY, Celia Lessa. (2012), O Estado do Bem-estar Social na Idade da Razão: A Reinvenção do Estado Social no Mundo Contemporâneo. Rio de Janeiro, Campus/Elsevier.

. (2011), “Welfare State e Desenvolvimento". Dados, vol. 54, no 1, pp. 129-156.

. (2010), “Social Development in Latin America?". Texto para Discussão CEDE, no 26. Disponível em http://www.proac.uff.br/cede/sites/default/files/TD026_1.pdf.

KOSTER, F. (2009). "The welfare state and globalisation: down and out or too tough to die?", International Journal of Social Welfare, vol. 18, n. 2, p. 153-162.

MANN, Kirk. (2009), “Remembering and Rethinking the Social Divisions of Welfare: 50 Years On". Journal of Social Policy, vol. 38, no 1, pp. 1-18.

MARQUAND, David. (2004), Decline of the Public. Cambridge, UK, Polity Press.

NULLMEIER, Frank e KAUFMANN, Franz-Xaver. (2010), “Post-Welfare State Development", in F. Castles et alii (eds.), The Oxford Handbook of the Welfare State. Oxford, Oxford University Press, pp. 61-81.

O'CONNOR, James. (1973), The Fiscal Crisis of the State. New York, St Martin's Press.

OECD (Organisation for Economic Co-operation Development. (2009), Social Expenditure Database. Disponível em http://www.oecd.org/document/9/0,3746,en_2649_ 33933_38141385_1_1_1_1,00.html. Acessado em 13 de julho de 2011.

. (2008), Growing Unequal? Income Distribution and Poverty in OECD Countries. Paris, OECD.

(2007), Social Expenditure Database: An Interpretive Guide SOCX 1980-2003. Disponível em http://stats.oecd.org/OECDStatDownloadFiles/OECDSOCX2007InterpretativeGuide_En.pdf. Acessado em 22 de fevereiro de 2011.

(1988), The Future of Social Protection. Paris, OECD.

PALIER, Bruno. (2010), "Continental Western Europe", in F. Castles et alii (eds.), The Oxford Handbook of the Welfare State. Oxford, Oxford University Press, pp. 601-616.

PENG, Ito e WONG, Joseph. (2010). "East Asia”, in F. Castles et alii (eds.), The Oxford Handbook of the Welfare State. Oxford, Oxford University Press, pp. 656-671.

PIERSON, Christopher. (2006), Beyond the Welfare State: The New Political Economy of Welfare (3a ed.). Cambridge, Polity Press.

(1998), Beyond the Welfare State: The New Political Economy of Welfare. Cambridge, Polity Press. 
Sobre a "Crise" do Estado de Bem-Estar: Retração, Transformação Fáustica...

PIERSON, Paul. (1996), “The New Politics of the Welfare State". World Politics, vol. 48, no 2, pp. 143-179.

RODRIK, Dani. (1996), “Why do More Open Economies Have Bigger Governments?". NBER Working Papers 5537, National Bureau of Economic Research, Inc.

ROTHGANG, Heinz, OBINGER, Herbert e LEIBFRIED, Stephan. (2006), “The State and its Welfare State; How do Welfare State Changes Affect the Make-up of the Nation-State". Social Policy and Administration, vol. 40, no 3, pp. 250-266.

SCRUGGS, Lyle e ALLAN, James. (2004), Welfare State Decommodification and Poverty in Advanced Industrial Democracies. Trabalho apresentado na 14a International Conference of Europeanists, Palmer House Hilton, Chicago, IL, 11-13 de março.

SEELEIB-KAISER, Martin (ed.). (2008), Welfare State Transformations: Comparative Perspectives. Basingstoke, Palgrave MacMillan.

SKOCPOL, Theda. (1995), Social Policy in the United States. Princeton, Princeton University Press.

STARKE, Peter; OBINGER, Herbert e CASTLES, Francis G. (2008), "Convergence Towards Where: In What Ways, if Any, Are Welfare States Becoming More Similar?". Journal of European Public Policy, vol. 15, no 7, pp. 975-1000.

TAYLOR-GOOBY, Peter. (2002), "The Silver Age of the Welfare State". Journal of Social Policy no 31, pp. 597-621.

TITMUSS, Richard. (1974), Social Policy: An Introduction. New York, Pantheon Books. 


\section{ANEXO 1}

Tabela 2

Indicadores de Gasto Social - Média OECD

$(1960,1980,1998)$

\begin{tabular}{lccccc}
\hline & $\mathbf{1 9 6 0}$ & $\mathbf{1 9 8 0}$ & $\mathbf{1 9 9 8}$ & $\mathbf{1 9 8 0 - 1 9 6 0}$ & $\mathbf{1 9 9 8 - 1 9 8 0}$ \\
\hline GS \% PIB & 10,1 & 18,7 & 22,7 & 8,6 & 4 \\
GS/GPT & 36,1 & 43,5 & 52,4 & 7,4 & 8,9 \\
GS/dependente & ND & 1,04 & 1,03 & - & 0,01 \\
GS real per capita* & ND & 2004 & 3413 & - & 1409 \\
GS real/dependente* & ND & 11374 & 15557 & - & 4183 \\
\hline
\end{tabular}

Fonte: Elaboração própria com base nos dados de Castles (2004).

GS = gasto público social; GS/GPT = gasto público social sobre gasto público total; GS/dependente = gasto público social por dependente.

*Em dólares norte-americanos de 1985. 
Sobre a "Crise" do Estado de Bem-Estar: Retração, Transformação Fáustica...

\section{ANEXO 2}

\section{Indicadores de Gasto Social 2000-2007}

Os indicadores quantitativos do gasto social não revelaram uma quebra no crescimento do welfare state na década de 2000. De fato, apesar da pequena redução observada na relação gasto/produto em 2007 em relação a 1998, o montante real de recursos comprometidos, seja per capita seja por dependente, aumentou significativamente. Quanto à convergência, observada entre os anos 1980 e 1998, não se verificou para o gasto real per capita ou por dependente entre os anos 2000 e 2007, remetendo à diferenciação entre os regimes.

\section{Gráfico 6}

Indicadores de Gasto Social (\%)

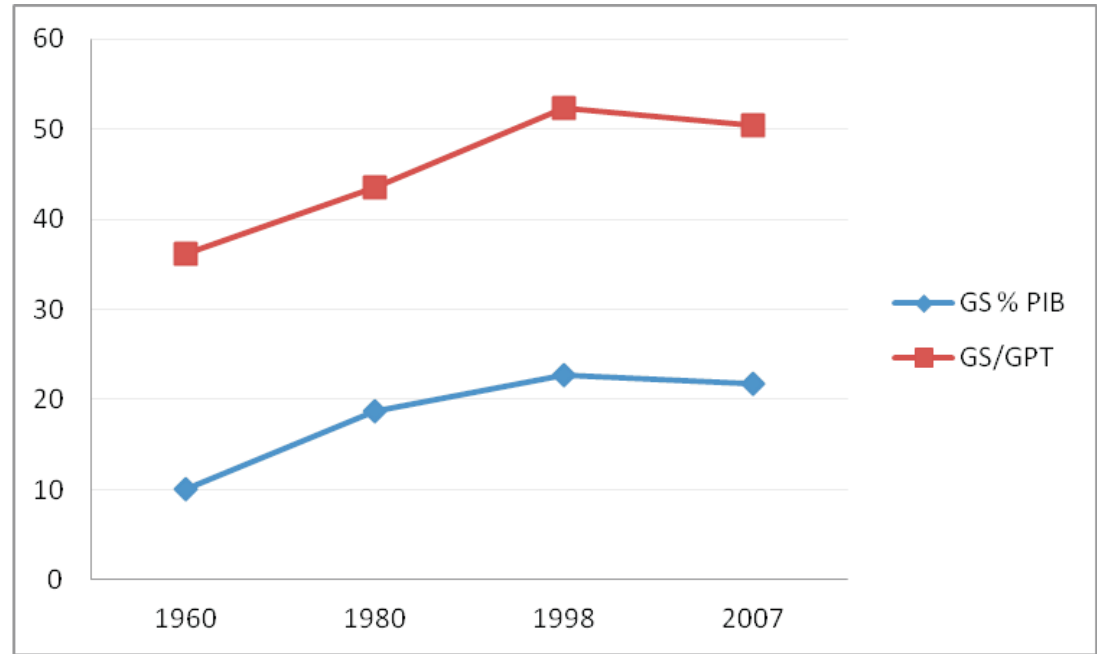

Fonte: Expenditure Database (OECD, 2009). 


\section{Gráfico 7}

Indicadores de Gasto Social

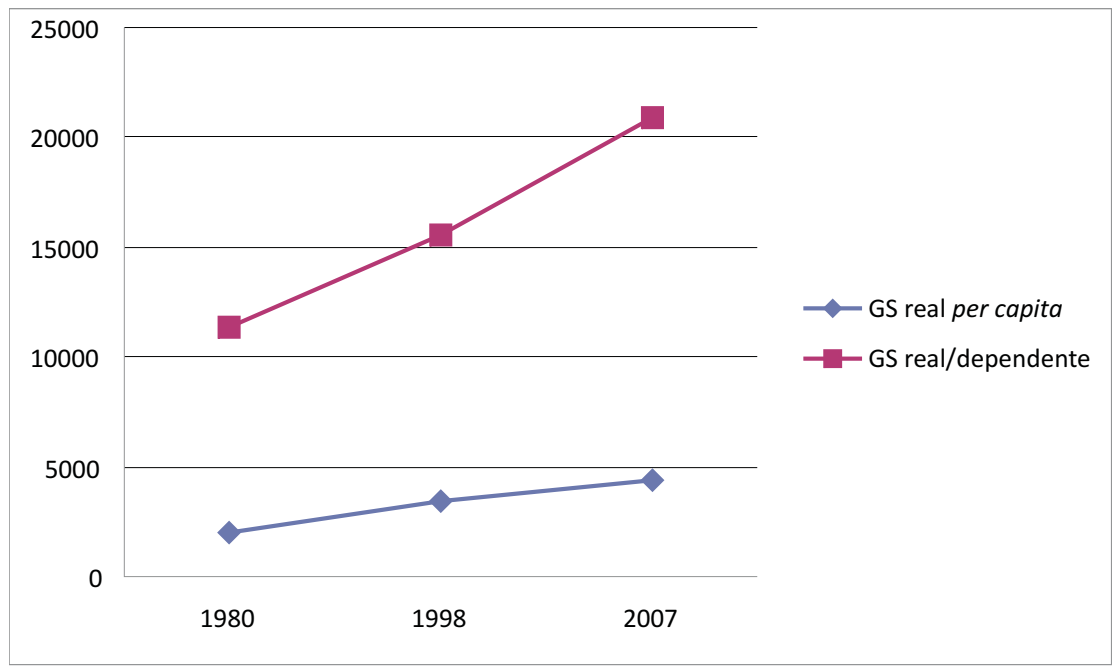

Fonte: Expenditure Database (OECD, 2009).

\section{Gráfico 8}

Coeficientes de Variação

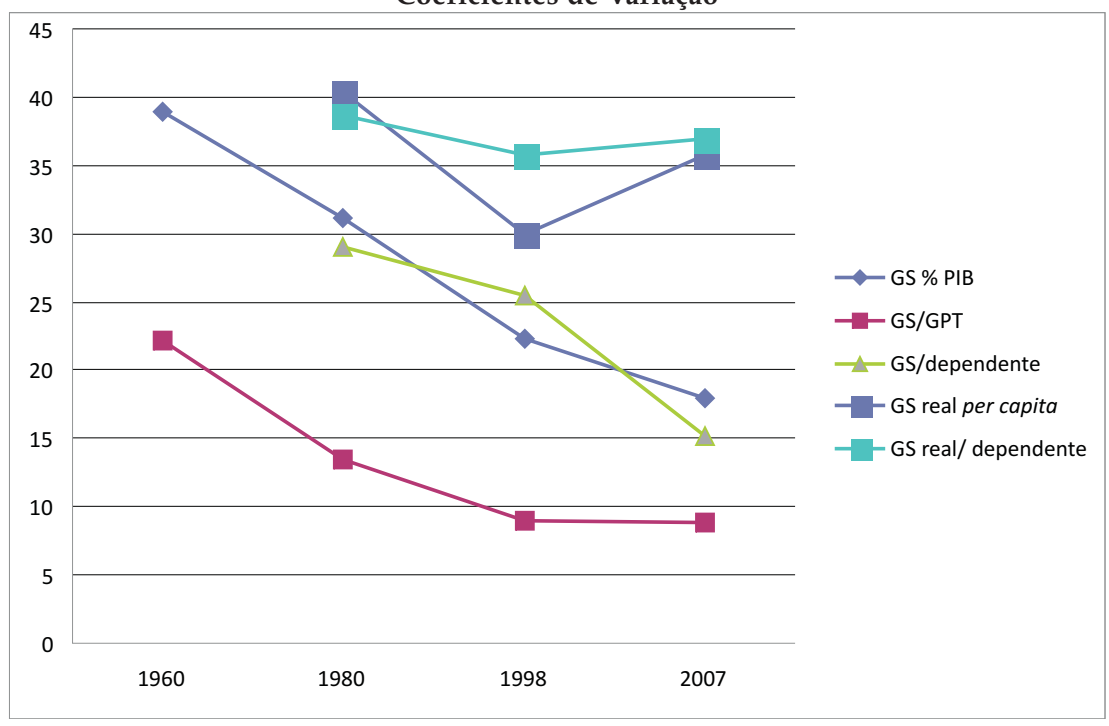

Fonte: Elaboração própria com base em dados de Castles (2004). 


\section{ABSTRACT \\ On the "Crisis" in the Welfare State: Retrenchment, Faustian Transformation, or What?}

The crisis in the welfare state has been announced for nearly four decades, prophesying its retrenchment or even its imminent demise. The article examines this position, based on an operational definition of welfare state, the meanings ascribed to its crisis, and a compilation of the available evidence, and concludes that while the scenarios of retrenchment and imminent demise can be ruled out, other perils such as the privatization of social policies appear to be more serious. The conclusions suggest that the extent to which such hazards represent a negotiation of the welfare state's soul needs to be evaluated not only in economic and financial metrics, but also through a normative framework.

Key words: welfare state; welfare state crisis; private social policies; public domain; political economy

\section{RÉSUMÉ}

Sur la "crise" de l'Etat Providence: retrait, transformation à la Faust ou quoi de plus?

Depuis presque quarante années, on annonce une crise de l'Etat Providence envisageant son retrait ou même sa fin proche. Dans cet article on examine cette proposition à partir d'une définition opérationnelle de l'Etat Providence, de significations attribuées à sa crise et de la réunion des preuves dont on dispose, pour conclure que, tandis que des scénarios de retrait et de fin proche peuvent être écartés, d'autres dangers tels que la privatisation des politiques sociales, semblent plus menaçants. On suggère, pour conclure, que l'étendue de ces dangers visant une négociation de l'âme de l'Etat Providence doit être évaluée non seulement selon des critères économiques et financiers, mais aussi par des considérations normatives.

Mots-clés: Etat Providence; crise de l'Etat Providence; politiques sociales privées; domaine public; économie politique 